\title{
Learning from one another: evaluating the impact of horizontal knowledge exchange for environmental management and governance
}

\author{
Céline Tschirhart ${ }^{1}$, Jayalaxshmi Mistry ${ }^{1}$, Andrea Berardi ${ }^{2}$, Elisa Bignante $^{3}$, Matthew Simpson $^{4}$, Lakeram Haynes $^{5}$, Ryan Benjamin $^{5}$, \\ Grace Albert $^{5}, \underline{\text { Rebecca Xavier }}^{5}$, Bernie Robertson $^{5}$, Odacy Davis $^{6}$, Caspar Verwer $^{7}$, Géraud de Ville $^{2}$ and Deirdre Jafferally $^{6}$
}

\begin{abstract}
There is increasing advocacy for inclusive community-based approaches to environmental management, and growing evidence that involving communities improves the sustainability of social-ecological systems. Most community-based approaches rely on partnerships and knowledge exchange between communities, civil society organizations, and professionals such as practitioners and/or scientists. However, few models have actively integrated more horizontal knowledge exchange from community to community. We reflect on the transferability of community owned solutions between indigenous communities by exploring challenges and achievements of community peer-to-peer knowledge exchange as a way of empowering communities to face up to local environmental and social challenges. Using participatory visual methods, indigenous communities of the North Rupununi (Guyana) identified and documented their community owned solutions through films and photostories. Indigenous researchers from this community then shared their solutions with six other communities that faced similar challenges within Guyana, Suriname, Venezuela, Colombia, French Guiana, and Brazil. They were supported by in-country civil society organizations and academics. We analyzed the impact of the knowledge exchange through interviews, field reports, and observations. Our results show that indigenous community members were significantly more receptive to solutions emerging from, and communicated by, other indigenous peoples, and that this approach was a significant motivating force for galvanizing communities to make changes in their community. We identified a range of enabling factors, such as building capacity for a shared conceptual and technical understanding, that strengthens the exchange between communities and contributes to a lasting impact. With national and international policy-makers mobilizing significant financial resources for biodiversity conservation and climate change mitigation, we argue that the promotion of community owned solutions through community peer-to-peer exchange may deliver more long-lasting, socially and ecologically integrated, and investment-effective strategies compared to top-down, expert led, and/or foreign-led initiatives.
\end{abstract}

Key Words: best practices, community owned solutions, environmental governance, Guiana Shield, Guyana, indigenous, knowledge exchange, participatory, visual

\section{INTRODUCTION}

As a result of escalating and converging environmental, social, and economic challenges, community empowerment has been a response to dealing with the complex and unpredictable nature of environmental management and governance (Kapoor 2001). There are increased calls for a shift away from top-down, expertled (usually foreign) decision-making through strengthening local and institutional capacity for participatory environmental management. This, as Rodriguez et al. (2006) point out, has the potential to help communities in biodiversity-rich developing countries take the lead in finding long-term sustainable solutions to their own environmental management and conservation/ poverty dilemmas.

Historically, capacity building and training activities (the core of many developed world, donor funded, conservation and development projects and interventions) have focused heavily on delivering a "product" and trying to provide local people with "prescriptive advice" rather than developing their abilities to work through complex problems themselves (Kaplan 2000, Black 2003). Reasons for this include the short timeframe within which many of these projects run, which thereby restricts innovative learning approaches and the development of "soft" skills that evidently take time to develop, as well as the agendas of funding bodies, development/conservation agencies, and practitioners, which often focus on promoting their own interests (see Mistry et al. 2009, 2011). There is also a need for a change in mind-setwith a move away from dependency on past blueprint solutions and trained behaviors, and instead freeing participants to respond individually to unique situations (Kaplan 2000). Capacity building for participatory environmental management should "create enabling conditions for learning which...involve a concern with issues of power, culture, institutions, worldviews and values" (Armitage et al. 2008:96). Also, as Eade (2007) points out, real capacity is built only when it contributes to enabling participants themselves to change their own realities. Thus, the challenge lies in the development of approaches that can create these enabling conditions.

In order to tackle increasingly complex social-ecological challenges, over the past decade there have been calls to integrate and take into account different types of knowledge emerging from different stakeholders, based on the argument that the sole perspective of Western science and its systems of knowledge are not sufficient for the understanding of, and acting upon, multiscalar and systemic challenges (Olsson and Folke 2001). Indeed, local knowledge that is grounded in specific contexts, adaptive to changing environments, and situated within numerous interlinked facets of people's lives is now often considered to be key to solving complex social-ecological challenges, such as adapting to the effects of climate change (e.g., Newsham and Thomas 2011, Fu et al. 2012). This acknowledgment has led to the development of

${ }^{1}$ Royal Holloway University of London, UK, ${ }^{2}$ The Open University, UK, ${ }^{3}$ University of Torino, Italy, ${ }^{4}$ Wildfowl \& Wetlands Trust (Consulting) Ltd, UK, ${ }^{5}$ North Rupununi District Development Board, Guyana, ${ }^{6}$ Iwokrama International Centre, Guyana, ${ }^{7}$ IUCN National Committee of The Netherlands, The Netherlands 
many mechanisms through which scientific and local knowledge could be shared for supporting social-ecological sustainability, such as community-based natural resource management (Berkes 2007) and adaptive comanagement (Olsson et al. 2004, Armitage et al. 2007). Participatory and empowering processes have been placed at the center of these approaches to ensure increasing ownership of the process by the communities concerned.

Knowledge exchange between a wide range of stakeholders and disciplines is gaining prominence, based mainly on a subjectivist view of knowledge (Fazey et al. 2014). Knowledge exchange and the coproduction of knowledge (e.g., Mauser et al. 2013, Reed et al. 2014) place communities within an extensive network of stakeholders at different scales, who join their forces to solve a specific issue. Although knowledge exchange is presented as an innovative move forward, Fazey et al. (2014) also point out that this mechanism still lacks a validated conceptual framework and evaluation method to assert its effectiveness. To answer these concerns, Reed et al. (2014) assessed ways in which knowledge exchange can lead to better practice, and effectively inform policy. They underlined five principles: (1) design knowledge exchange into the research; (2) represent user knowledge needs and priorities; (3) build long-term, trusting relationships based on dialogue; (4) deliver tangible results as soon as possible; and (5) monitor and reflect on the experience in order to improve and guarantee legacy of the process. Fazey et al. (2014), on the other hand, focusing on the particular topic of the evaluation of knowledge exchange, proposed five principles for knowledge exchange evaluation to strengthen the practice: (1) design for multiple end users; (2) be explicit about how you conceptualize knowledge in the process; (3) evaluate diverse outcomes; (4) practice participatory evaluations; and (5) use mixed methods for evaluation. Although these papers were published after we initiated our knowledge exchange process, the principles suggested are those that are shared by many experienced practitioners who are involved in the knowledge exchange field, and which some of this paper's authors have learned the hard way, having reflected on the failure of particular approaches to research that involved participants from developing country contexts (see Mistry et al. 2009).

While the inclusion of local communities in decision-making at all levels of environmental management and governance has been presented as crucial for capacity building and social-ecological integrity, there are also strong critiques of participatory community-based approaches, summarized in Measham and Lumbasi (2013), including a lack of autonomy in contexts where higher level stakeholders are often supervising the interventions. For example, Palmer Fry et al. (2015) described the "power struggle" that occurs between marginalized community members and other stakeholders, such as NGO employees and government officials, in determining which conceptualizations and approaches are used for determining and improving community well-being within conservation interventions, and therefore what is monitored during such interventions. In contrast, community owned initiatives where the approach focuses on issues relevant to communities' livelihoods and beliefs, and enables greater levels of community autonomy within a project, can have better success (Mistry et al. 2016). In essence, the main issue at stake seems to be the distribution of decision-making power within multistakeholder environmental management interventions, where community members are seldom the ones to initiate and lead the processes.

To promote better practice and positive impact, support socialecological integrity, and empower local communities, there is therefore a need for alternative ways of promoting local knowledge and practices through less hierarchical mechanisms. One way of achieving this goal is through community peer-topeer knowledge exchange. It is important to clarify here that different types of knowledge exchange involving communities can take place. Some of them involve knowledge exchange between communities and other stakeholders, such as government agencies and academia. Our particular focus is on knowledge exchange that takes place between communities; hence, the rather convoluted, but accurate, description of our knowledge exchange approach is "Community Peer-to-Peer Knowledge Exchange" (CP2PKE).

There is growing recognition of the role of CP2PKE in environmental management, with a range of institutions at all levels of governance beginning to support the adoption of more "horizontal" models of capacity building, in which knowledge is shared among communities themselves (e.g., UNDP 2014, World Bank 2015). Based on programs carried out initially in India, and then throughout Asia and Africa in the 1990s, Patel and Mitlin (2002) discussed some of the strengths of CP2PKE through which poor urban communities can share information with one another. They observed that CP2PKE created a climate of trust where participants were more willing to share their experiences, knowledge, and challenges. Feedback was given through a peerto-peer process, and learning techniques from peers built confidence in the learning process, as it seemed more achievable when peers had demonstrated their own ability to learn as well. The level of ownership of the process was high, since challenges and solutions were shared and self-determined, and the pace of progress and management of local dynamics was controlled by communities themselves. Receiving individuals from other communities stimulated curiosity and participation, and although leaders were involved, they were not allowed to dominate the process, as is often the case in more vertical approaches. Similar results were found by Wahbe et al. (2007) during a health CP2PKE between indigenous communities in Ecuador and Canada. In addition, the authors highlighted the increased motivation to instill positive change, the empowerment of a wide range of community members, and the re-evaluation of cultural values in the process.

We describe a CP2PKE where community owned solutions for addressing social-ecological challenges were shared between indigenous communities living in the Guiana Shield region of South America. By analyzing the empirical data collected during the knowledge exchange process, we present practical and original criteria for evaluating the success of the transferability process and the impact of the knowledge exchange on the communities.

\section{RESEARCH CONTEXT}

The CP2PKE we evaluated took place under the umbrella of Project COBRA, a three and a half year research project financed by the European Union (see http://www.projectcobra.org). The aim of this international, multidisciplinary, multistakeholder project was to identify, document, and promote community owned solutions for the management of natural resources in the 
Guiana Shield, South America, and for determining the most effective and efficient use of emerging funding streams in order to promote social justice and ecological sustainability. We worked in four stages: Stage 1: Developing a shared cross-scalar and interdisciplinary understanding of the factors that may influence community social-ecological survival (see Berardi et al. 2012, 2013a, b, 2015); Stage 2: Exploring future scenarios affecting social-ecological resilience across local, national, and international scales (see Mistry et al. 2013a, 2014a); Stage 3: Identifying practices for operationalizing ideal cross-scalar models for social-ecological survival, namely by identifying community survival strategies "best practices" (see Mistry et al. 2013b, 2016); and Stage 4: Building wider capacity and sharing, and applying "community survival strategies" best practice in other communities and civil society organizations (CSOs) (see Tschirhart et al. 2014).

In Stages 1-3 of the project and at the local level, the research focused on the North Rupununi region of Guyana. Overarching the whole project were three related research approaches: participatory action research (Kindon et al. 2007)-where reflection and learning, as well as the needs of the participants involved in the project, were built into the way the project functioned; system viability (Berardi et al. 2015) - a holistic framework through which communities assessed their responses to a range of social-environmental challenges; i.e., community survival strategies; and participatory visual methods-namely Participatory Video (PV) and Participatory Photography (PP) (Lunch and Lunch 2006, Bignante 2010, Mistry and Berardi 2012), tools that allow people to represent their own views and concerns in an accessible way. In addition, indigenous community researchers carried out and led all field-related activities, including community engagement, PV and PP recordings, and sharing. Reporting and reflection on all these approaches are presented elsewhere (see Berardi et al. 2013b, Mistry et al. 2014b, 2015a, $b$ ). We present results only from Stage 4, the final phase of the project involving CP2PKE between communities.

\section{Community exchange process}

Stages 1-3 of Project COBRA enabled indigenous communities in the North Rupununi, Guyana to identify and record six best practices for community survival through the use of the system viability conceptual framework and the use of PV and PP (see Mistry et al. 2013b and Mistry et al. 2016). These best practices were traditional fishing techniques, the setting up of a community radio station, community self-help practices, traditional farming techniques, the development of partnerships through the local $\mathrm{CSO}$, and strategies for the transmission of indigenous culture to youths. This was the culmination of two years of participatory research with the communities and the development of a community engagement process through the use of PV and PP. A team of five indigenous facilitators (composed of two females and three males) was employed by a partner indigenous CSO on the project to facilitate the community engagement process of best practices identification in the North Rupununi. This process had been documented and tested in the form of a handbook (see Berardi et al. 2014a) so it could be used as a capacity building tool with other communities. Capacity building in other communities involved:
1. sharing the project concepts and techniques with other communities, discussing them, and adapting them to the local context;

2. presenting the North Rupununi best practices to other communities as a source of inspiration for them (and reflection on similar issues involving the community); and

3. engaging these communities in identifying and sharing their own best practices.

During the exchanges, the handbook formed the basis of the activities that took place, and laid the foundations for a shared understanding in terms of concepts and techniques.

Through discussions with established CSOs in the region, six communities from the different countries of the Guiana Shield that may have had similar social-ecological challenges as the North Rupununi were invited to carry out the exchange (Fig. 1): Kwamalasamutu, a Trio community in Suriname; Kavanayén, a Pemon Arekuna community in Venezuela; Katoonarib, a Wapishana community in Guyana; Maturuca, a Makushi community in Brazil; Laguna Colorada, a Sikuani community in Colombia; and Antecume Pata, a Wayana community in French Guiana. Since all of these communities were unknown to the Project COBRA members, their engagement involved the support of CSOs that had extensive and long-term experience of working with these communities. These CSOs also participated in the exchanges by giving support in communication, facilitation, logistics, and ethics, and at the same time helped monitor and evaluate progress and impact. The teams engaged in facilitating the CP2PKE were therefore composed of two or three indigenous community facilitators from the North Rupununi (termed "community facilitators"), one or two national CSO staff members with strong ties to the communities (termed "CSO support"), and one to three non-indigenous project researchers/ practitioners (termed "project practitioners").

Fig. 1. Indigenous communities of the Guiana Shield involved in the exchanges. The best practices that formed the basis of the knowledge exchange were developed primarily from the North Rupununi, Guyana, including the communities of Apoteri, Fairview, and Rupertee (Drawing credit: Jenny Kynaston).

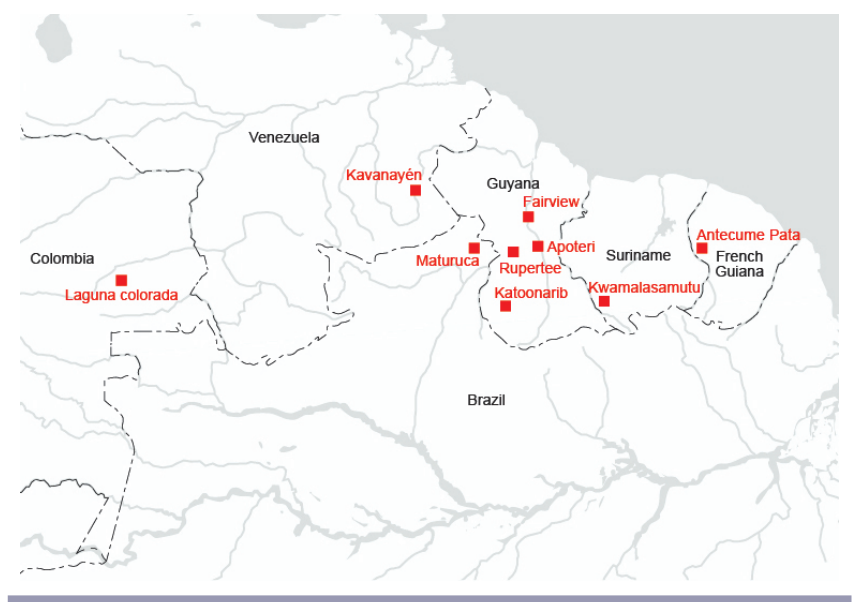


Table 1. Overview of community engagement during exchanges.

\begin{tabular}{|c|c|c|c|c|c|c|c|c|c|c|}
\hline Community & Country & $\begin{array}{l}\text { First visit } \\
\text { in }\end{array}$ & $\begin{array}{l}\text { Last visit } \\
\text { in }\end{array}$ & $\begin{array}{l}\text { Number } \\
\text { of visits }\end{array}$ & $\begin{array}{l}\text { Length of } \\
\text { engagement } \\
\text { (months) }\end{array}$ & $\begin{array}{l}\text { Type of civil } \\
\text { society } \\
\text { organization } \\
\text { supporting } \\
\text { COBRA }\end{array}$ & $\begin{array}{l}\text { Average } \\
\text { size of } \\
\text { COBRA } \\
\text { team to } \\
\text { facilitate } \\
\text { process }\end{array}$ & $\begin{array}{l}\text { Number of } \\
\text { local } \\
\text { participants } \\
\text { at beginning } \\
\text { of work }\end{array}$ & $\begin{array}{l}\text { Number of } \\
\text { local } \\
\text { participants } \\
\text { at end of } \\
\text { work }\end{array}$ & $\begin{array}{c}\text { Translations } \\
\text { needed }\end{array}$ \\
\hline Kwamalasamutu & Suriname & $\begin{array}{c}\text { October } \\
2013\end{array}$ & June 2014 & 3 & 9 & $\begin{array}{c}\text { National } \\
\text { CSO }\end{array}$ & 6 & 9 & 5 & $\begin{array}{l}\text { Trio-Dutch- } \\
\text { English }\end{array}$ \\
\hline Kavanayén & Venezuela & $\begin{array}{c}\text { December } \\
2013\end{array}$ & June 2014 & 3 & 7 & $\begin{array}{l}\text { National } \\
\text { university }\end{array}$ & 6 & 9 & 7 & $\begin{array}{l}\text { Spanish- } \\
\text { English }\end{array}$ \\
\hline Katoonarib & Guyana & $\begin{array}{c}\text { January } \\
2014\end{array}$ & June 2014 & 4 & 6 & $\begin{array}{c}\text { National } \\
\text { CSO }\end{array}$ & 3 & 12 & 6 & None \\
\hline Maturuca & Brazil & $\begin{array}{c}\text { January } \\
2014\end{array}$ & June 2014 & 2 & 6 & $\begin{array}{c}\text { National } \\
\text { CSO }\end{array}$ & 3 & 3 & 3 & $\begin{array}{l}\text { Portuguese- } \\
\text { English }\end{array}$ \\
\hline $\begin{array}{l}\text { Laguna } \\
\text { Colorada }\end{array}$ & Colombia & April 2014 & $\begin{array}{c}\text { September } \\
2014\end{array}$ & 2 & 6 & $\begin{array}{c}\text { National } \\
\text { CSO }\end{array}$ & 5 & 10 & 10 & $\begin{array}{l}\text { Spanish-- } \\
\text { English }\end{array}$ \\
\hline $\begin{array}{l}\text { Antecume } \\
\text { Pata }\end{array}$ & $\begin{array}{l}\text { French } \\
\text { Guiana }\end{array}$ & May 2014 & July 2014 & 2 & 3 & $\begin{array}{l}\text { National } \\
\text { university } \\
\text { and CSO }\end{array}$ & 5 & 7 & 5 & $\begin{array}{l}\text { French- } \\
\text { English }\end{array}$ \\
\hline
\end{tabular}

The initial schedule for the exchanges involved three trips over a period of six to nine months. However, due to logistical realities such as project funding constraints, limited access to some areas and communities, time taken to obtain visas, and the restricted period to deliver the program, exchanges varied between communities. An overview of the exchanges is given in Table 1.

The first trip to each community, which lasted between five and 10 days, involved presenting the project to the community and addressing any queries they had about the aims of the CP2PKE; working with the community's governance structure to select up to 12 local community members who could work with the project over the next few months; training these community members in the concepts and practical methods of the project; identifying the community's own best practices; identifying which North Rupununi best practice may be used to tackle one or more of the community's challenges; and developing a plan of implementation and documentation. These activities were carried out using our participatory, visual, and systemic methodological approach outlined in the COBRA handbook (Berardi et al. 2014a). During the days spent in the community, many community screenings also took place to present the training outputs and North Rupununi best practices to the wider community. At the end of the training, a team of up to 10 trainees was left in charge of documenting their community owned solution and implementing the North Rupununi best practice (Table 2).

The second trip of between five and seven days occurred after a period of two to four months, with the objective to evaluate progress and provide further support and capacity building in project concepts and methods. A final trip of between five and seven days was organized after another period of two to four months to carry out a final assessment of the best practices transferability and its impact on the community and local participants. During these last trips, support was also given to finalize the community's films and photostories. All of these can be viewed on the Project COBRA website. Finally, discussions were carried out to plan future community-based activities using the project concepts and methods in order to encourage the sustainability of the project intervention. This included preparations for, and attendance at, a Guiana Shield Indigenous Participatory Film Festival, which invited all community members involved in the project to showcase their community owned solutions. The film festival took place in Georgetown, Guyana in September 2014.

\section{KNOWLEDGE EXCHANGE EVALUATION}

Our evaluation of the CP2PKE involved two tasks: firstly, an assessment of the capacity building of participants, which focused on developing a shared understanding of the concepts (e.g., community owned solutions, system viability) and communication approach (PP and PV). We hypothesized that the CP2PKE would be more effective if communities that spoke different languages and had distinct histories could at least share common concepts and techniques. This laid the groundwork for the second part of the CP2PKE evaluation, which investigated the impact of the sharing of best practices. In particular, we wanted to focus on investigating whether the CP2PKE of best practices inspired communities to take action in relation to their own challenges. Part of this investigation also looked at the impact of practical issues on the CP2PKE, such as the length of community engagement and the impact of language barriers.

Within the project, the evaluation carried out was established in order to find out whether (1) participants in the project engaged with the general objectives of the CP2PKE, and discussed and redefined these objectives to suit their specific context and culture; (2) participants were able to interpret the concepts and the tools used to carry out the CP2PKE through their own culturally specific understanding, and whether they critically engaged with these concepts and tools, and proposed their views and interpretation on them, leading to a redefinition of concepts and tools in a locally owned way; (3) participants engaged with their wider community to help in the presentation, discussion, and implementation of the North Rupununi best practices; and (4) the North Rupununi best practices had an impact on host communities (as a source of inspiration for developing their own 
Table 2. Solutions, challenges, and North Rupununi best practices chosen to implement in the six communities of the Guiana Shield.

\begin{tabular}{|c|c|c|c|}
\hline Community & Local community owned solution & Main challenge identified & $\begin{array}{l}\text { North Rupununi best practice chosen to } \\
\text { be implemented in response to the main } \\
\text { challenge identified }\end{array}$ \\
\hline Antecume Pata & Fishing practices & $\begin{array}{l}\text { Lack of community togetherness and } \\
\text { local governance }\end{array}$ & $\begin{array}{l}\text { A local COBRA team for self- } \\
\text { representation and voicing concerns }\end{array}$ \\
\hline Katoonarib & Forest island management & Culture loss & Culture group \\
\hline Kavanayén & Tourism cooperative & Culture loss & Culture group \\
\hline Kwamalasamutu & Two-farm system & $\begin{array}{l}\text { Lack of community togetherness and } \\
\text { local governance }\end{array}$ & Self-help to rebuild village bridge \\
\hline Laguna Colorada & Traditional cultural education & $\begin{array}{l}\text { Lack of communication facilities } \\
\text { between communities }\end{array}$ & Community radio \\
\hline Maturuca & Cattle raising to assert land rights & $\begin{array}{l}\text { Lack of communication facilities } \\
\text { between communities }\end{array}$ & Community radio \\
\hline
\end{tabular}

practices for facing up to current and emerging challenges). This enabled us to develop a program for evaluating in what way the participants' capacity had been built, how this capacity was put in practice, and in what way this has benefited the wider community. In addition, we collected quantitative and qualitative data about participants, the community, the characteristics of each trip, and the teams facilitating the exchange to understand contextual factors that could influence the impact of the CP2PKE.

Table 3 shows the different forms of monitoring and evaluation that took place during the whole period of engagement with each community. In the three communities of Kwamalasamutu, Kavanayén, and Katoonarib, monitoring and evaluation took place during every visit, and more indepth impact work at the community level was possible. In Maturuca and Laguna Colorada, community impact was derived from the participants, consultant reports, and anecdotal evidence, such as email correspondences. In Antecume Pata, community impact was assessed but was limited by lack of wider participation. Furthermore, the local participants in Antecume Pata chose a North Rupununi solution that did not require much community involvement, which limited a comprehensive evaluation of the $\mathrm{CP} 2 \mathrm{PKE}$ in this case.

The assessment at the participant level was carried out through 78 individual interviews (26 COBRA participants over three trips), two focus groups, and five peer-to-peer interviews. In the case of the peer-to-peer interviews, this was where small groups of participants (2-4) discussed their experiences of the CP2PKE process, with one of them taking down notes of the highlights of the discussion. At the community level, we analyzed 115 individual questionnaires and the discussion transcript from one focus group. At the consultant level, 12 reports and evaluations were analyzed. Finally, 15 end-of-trip COBRA team group evaluations, as well as 17 reflective diaries, were also used as data to better understand the impact and success factors of the exchange. Both the consultant reports and COBRA team evaluations provided additional observations on the experiences of both the community participants and the wider community.

These data were organized into individual participant and community responses, and then coded to elicit themes related to the transferability of concepts and techniques, and the impact of implementation of best practices. All qualitative analysis took place using the NVivo software, with initial categories created in order to focus on the elements that would demonstrate the impact of our activities in the communities. However, it was an iterative process, and new categories emerged during the analyses, which were then incorporated into the final results.

\section{RESULTS}

The key themes that emerged for successful transferability of project approaches included indigenous facilitators as key participants in the exchange, peer-to-peer learning, and the design of the exchange and the local training context. Similarly, the local context played an important role in determining the impact of best practice sharing on communities, as was peer-to-peer learning. We will now explain these in detail.

\section{Criteria for successful transferability of project approaches}

Indigenous facilitators for peer-to-peer learning

Our results from the participant interviews demonstrate that the most popular perceived benefits from an indigenous exchange were "enjoying learning from them [the indigenous COBRA facilitators]," with six participants also indicating that it was "good to have an indigenous cultural exchange." The interviews and our own observations indicated that indigenous facilitators from the North Rupununi were able to explain the project concepts and techniques in their own words, and could give examples that people could relate to. Having an intimate experience of community challenges and dynamics, they would often adapt and deliver messages according to their indepth understanding of the local context. They also facilitated a climate of trust, as participants knew, and could see from the videos and photostories presented, that the facilitators came from similar backgrounds and could understand the local context better than non-indigenous facilitators. At the same time, local participants felt more at ease asking questions and coming forward with their ideas and views with the indigenous researchers. As one participant from Katoonarib says:

"When white person come, it's white man business. But with [Project COBRA indigenous facilitators], it's our own people."

Another participant from Katoonarib said that she "Liked it that not white people coming, but more Amerindians." A participant 
Table 3. Types of monitoring and evaluation undertaken in each community.

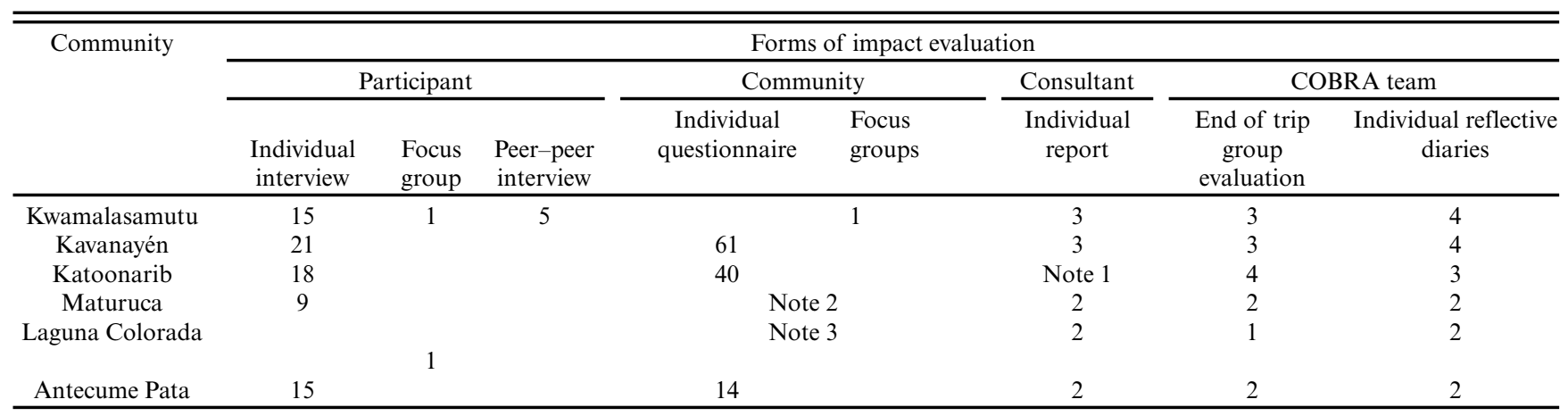

Note 1: There was no specific consultant involved in this exchange.

Note 2: For the Maturuca community, all activities took place in the North Rupununi, Guyana, not in the Maturuca community, due to institutional constraints. Therefore, all direct training and activities took place only with the Maturuca COBRA participants. There was no direct wider community engagement by the COBRA team; all community consultations were done through the participants and consultant.

Note 3: As a result of logistical issues, a second trip to this community by the COBRA team did not take place, so no direct monitoring of progress by the COBRA team occurred, although the consultant made a second visit and provided feedback.

from Antecume Pata mentioned that "they [Project COBRA indigenous facilitators] live like us a bit, they do cashiri, they hunt, they fish, they do everything, they party...we are the same." This community's local leader indicated that he would not have approved the project without the involvement of indigenous facilitators.

However, being an indigenous facilitator was not without its challenges. Some indigenous communities were used to nonindigenous professionals working for national and international agencies and/or on projects. Seeing an indigenous person taking the lead on community engagement was a new experience, which raised issues, both in the way the indigenous facilitators perceived themselves, and in the doubts about their role within some indigenous communities. These issues of positionality as an insider or outsider have been explored in detail by Mistry et al. (2015b).

Peer-to-peer learning for concepts and technique transferability In terms of concepts, indigenous facilitators could illustrate ideas with a wide range of examples from their own communities. For example, in Antecume Pata, an understanding of community survival strategies was facilitated through drawings developed by community facilitators in order to illustrate their local understanding of the various strategies available to communities. This activity was perceived by participants to be engaging, and participants very quickly gained an understanding of the different survival strategies available to communities. In terms of techniques, many participants said they enjoyed learning how to use information and communications technology (ICTs) with the community facilitators. The fact that peers were able to manage the technologies and then teach them gave the participants confidence and conveyed the message that these were not just "white people's" tools. Furthermore, techniques could be taught, again, using their own understandings and language. For example, participants in Katoonarib said:

"When foreigners come, people say they are using us and our resources. When indigenous people come, who have shared their experience with the foreigners, we can see if it benefits, it gives us confidence. People from the North Rupununi have ideas how they can make things happen, how to improve."

"A [female indigenous facilitator] gave really nice explanationsshe has nice mind. I feel frightened to ask B [male indigenous facilitator], we're afraid to ask men. But she tells in easiest way. I learnt about equipment, meeting people, computer" (female participant, Katoonarib).

This last quote also underlines the success of having both males and females within the team of indigenous facilitators, as this helps ensure that all participants can be fully included in the process.

\section{Design of exchange and local training context}

Some of the key criteria that we analyzed were the effect of the number of visits and length of engagement with the community on the success, or not, of the CP2PKE. Our initial plan envisaged an engagement taking place over a period of approximately six months, with three visits to each community in order to deliver initial training, evaluate the process, and give support if necessary. However, as Table 1 shows, communities were not all engaged over the same length of time, nor did they have the same number of visits. The impact appears particularly clear for the community of Katoonarib. Here, participants benefited from four visits from community facilitators over a period of six months, which gave them many more opportunities to exchange with facilitators and deepen their understanding of concepts and techniques. Katoonarib was geographically and culturally quite close to the North Rupununi, within the same country and region, and was therefore the easiest community to reach. This enabled the indigenous researchers to independently organize a fourth trip to Katoonarib, with minimal involvement of project practitioners, in order to carry out a stronger follow-up of the project.

Logistics, budgeting, and planning to visit communities in distant and foreign settings were significantly more complex. Participants from the communities of Antecume Pata and Maturuca, which 
Table 4. Community participant team composition.

\begin{tabular}{|c|c|c|c|c|c|c|}
\hline & $\begin{array}{l}\text { Dominant } \\
\text { gender }\end{array}$ & Dominant age & $\begin{array}{l}\text { National } \\
\text { language spoken }\end{array}$ & $\begin{array}{l}\text { Profession, } \\
\text { occupation }\end{array}$ & $\begin{array}{l}\text { Past experiences } \\
\text { in projects }\end{array}$ & Hopes \\
\hline Antecume Pata & Male & Young & Well & $\begin{array}{l}\text { Mainly } \\
\text { subsistence }\end{array}$ & None & To learn \\
\hline Katoonarib & Female & Wide age range & Well & $\begin{array}{l}\text { Mainly } \\
\text { subsistence }\end{array}$ & Varied & To learn \\
\hline Kavanayén & Female & Mature adults & Well & $\begin{array}{l}\text { Teachers and } \\
\text { students }\end{array}$ & Several & $\mathrm{ICT}^{\dagger}+$ community issues \\
\hline Kwamalasamutu & Female & Young & Not well & Subsistence & None & ICT + community issues \\
\hline Maturuca & Balanced & Wide age range & Well & Wide range & Several & ICT + community issues \\
\hline
\end{tabular}

both showed low levels of understanding of concepts and techniques, were visited only twice. In Antecume Pata, only two trips were carried out over a period of three months. As the CSO support states in her evaluation of the final trip, "they fairly understood the purpose of the project (medium level). Nevertheless, I think a third visit in the community would have increased the level of understanding of the purpose of the project."

Another criterion that we focused on in the evaluation of the impact of the CP2PKE was the composition of the team that delivered the capacity building. This was a key factor, especially in the first trip, where a community was engaged for the first time, and key workshops were taking place to transmit an understanding of the project and its core aims and approaches. The tasks carried out by the different members in charge of delivering the training on the first trip were numerous: meeting with community leaders, planning for delivery of the workshops, facilitating the workshops, translating, evaluating activities, supporting the process, adapting the process according to the context, engaging with the whole community and the supporting CSOs, and capacity building. Our results show that there was an optimal team composition for an effective exchange:

- at least two indigenous facilitators (male and female);

- at least one CSO support with extensive experience of engagement with the local community; and

- at least two project practitioners (with at least one with extensive experience of concepts and techniques, and one in charge of translations, if necessary).

Local to national CSOs are crucial in order to implement an exchange, especially within a short period of time. In our case, they had indepth knowledge of the context, extensive knowledge of the participants and community dynamics, and could advise on appropriate methods and techniques to engage with the participants and the wider community. CSOs also monitored activities between the exchange visits and provided useful information for adapting our standard methods according to the context. Our CSO support also ensured that proper protocol was followed in order to have as much community engagement as possible.

Project practitioners' tasks were to support the process of delivering the activities (planning, adapting, discussing) and evaluating the process. Project practitioners also had the responsibility of building the capacity of indigenous facilitators. In some cases, project practitioners also had to carry out translations during workshops. Our results indicate that the bigger the team of practitioners is on the first trip, the higher the chances are of transferring concepts and building capacity in the use of techniques. In Katoonarib, where the highest levels of understanding and technical competency were reached, three project practitioners were present on the first trip, most of whom had several years of experience in community capacity building. This was in addition to two indigenous facilitators. Being a bigger team meant that tasks could be divided between several people, and therefore, the delivery of the training could be more timeefficient.

We also evaluated the impact of the characteristics of local participants on the CP2PKE (Table 4). Some key characteristics of local participants can help explain the success or challenges in engaging participants in concepts and techniques. These include experience of working in other projects, gender and age composition of the team, availability, and motivation. Our data show that a mixed team composed of young people and elders had a higher probability of understanding concepts and methods. Katoonarib's team of local participants had an age difference of 33 years between the oldest and the youngest participant. On the other hand, in Kwamalsamutu and Antecume Pata, where understanding was the lowest, the age range was only 10 years. In a mixed group, according to age, gender, and experiences in previous projects, different interpretations and perceptions could be developed. These different levels of understanding within the group of participants could be pooled and shared, thereby enhancing understanding and engagement. The sharing of views occurred during the workshops, as participants were encouraged to contribute their views, but also during practical activities and in the wider community engagement. Having a mixed team meant that different people were available at different times, so there was always a critical mass of participants to spend on the tasks. Participants had different types of responsibilities according to their age, gender, commitments, and occupations. This enabled collective ownership of the initiative, which in turn supported perseverance with implementation of tasks once the exchange visits had ended.

We also looked at the setting of the training as a potential characteristic that could determine the impact of the CP2PKE. In most contexts, initial engagement and training was carried out within the participants' communities. As a result, concepts and 
ideas presented could be very rapidly related to their own community context, especially during the training in PV and PP techniques, which involved practical activities within the community. This can be of significant help to encourage ownership of concepts, to give a familiar meaning to them. This could be one of the reasons why the participants from Maturuca had a relatively low level of understanding compared to other participants. They were invited to the North Rupununi (Guyana) in order to engage with the project and be trained. As a consequence, concepts were explored in a nonfamiliar context and did not allow these participants to gain a full ownership or understanding through an embedded, experiential learning process within their own communities.

An additional criterion for evaluating the impact of the CP2PKE was the quality of communication between facilitators and participants. An undeniable factor for building capacity in concepts and techniques is the fluidity of communication between community facilitators and local participants. However, in order to work with the communities of Antecume Pata, Maturuca, Kavanayén, Laguna Colorada, and Kwamalasamutu, translation was constantly required. One level of translation was required in Kavanayén and Laguna Colorada (Spanish-English), Antecume Pata (French-English), and Maturuca (Portuguese-English). Two to three levels of translation were needed in Kwamalasamutu (Trio-Surinamese/Dutch-English). As recorded in a field report, "this significantly impacted the dynamics of the workshops. Activities need to be significantly adapted if working in such a context, by making discussions/explanations as simple and concise as possible, with more emphasis on action. Otherwise, the activities become very difficult to follow for the participants." We observed that participants felt less shy about expressing their doubts or asking questions if they could address them directly to the indigenous facilitators rather than having to go through translators, who were often non-indigenous. Katoonarib, where a very good understanding of the CP2PKE process and objectives was achieved, was the only community where facilitators and local participants could communicate directly with each other. In Antecume Pata, one participant mentioned that although all discussions were translated in French, competency in French did not enable her to follow everything: "It [the training] was not too difficult, but what was difficult was the French, I forgot a bit how to speak French." Language was therefore a strong barrier during the exchange process. Although the CSO support and research team members were careful to translate accurately, the mere act of translation had the effect of diminishing the peer-to-peer interactivity, thereby taking a significant amount of time out of other activities. We would therefore suggest that the capacity to transfer concepts directly, peer-to-peer, without translations, would significantly enhance the process of transferability.

The final criterion that we looked at was the ICT experience and skills of participants. Previous ICT experience of the local participant team was a factor in the level of understanding reached in techniques and concepts. At the end of the community engagement, participants in Kavanayén, Maturuca, and Antecume Pata were technically more independent than participants from Katoonarib or Kwamalasamutu, who had no experience in ICT before the project. Teaching ICT skills can be extremely time-consuming, especially with participants who have barely touched a computer before. As a consequence, when significant time was needed for ICT capacity building, it became challenging to focus in great depth on building conceptual understanding. This was particularly the case in Kwamalasamutu, as the following quotes illustrate: "The participants had very limited (if any) IT skills. After two weeks, we had a feeling very few of them could carry out tasks independently. If working in such contexts and for only a limited period of time, it is important for the participants to practice these skills a little bit every day and as part of each activity" (project practitioner, Kwamalasamutu).

\section{Criteria for the impact of sharing best practices at community level}

Local factors affecting community best practice impact

Each community selected a best practice from the North Rupununi that was inspiring for the community to adapt and implement (Table 2). Table 5 summarizes the extent to which the best practice implementation was achieved, the main challenges and successes mentioned by participants and wider community members, and whether they had plans to continue the activities in the future. Results demonstrate that the most common reason given for the successful implementation of the best practice was effective interaction and engagement with the wider community, while common challenges included the absence of community engagement, lack of resources or funding, poor organization of the team, and lack of time. Difficulties in engaging the wider community depended on several reasons. One of them was the lack of participation of the community in events organized by the local team to promote the project activities. In Antecume Pata, for example, screening films and organizing meetings in the evenings to present the best practices attracted few members of the community. As a consequence, the community was widely illinformed about an important aspect of the project, which was the best practice exchange.

Moreover, in several contexts, the relatively young age of the local team members made it difficult for them to be heard by the rest of the community, especially when local leaders did not sufficiently support the activities. In Antecume Pata, although the leader had approved the project and gave all the technical support he could to guarantee good development of the capacity building events, he did not help in calling people for informative meetings, would not always attend the meetings, and would very seldom lead them. This impacted the project in the sense that the young local team lacked the initiative or courage to ensure that their work was being properly communicated to the rest of the village. A quote from a participant in Katoonarib illustrates this point: “... the Toshao [community leader] didn't show interest for the activity that was plan by the team... as a leader of the community, he should have shown some extent of attention to the work they are doing." On the other hand, in Kwamalasamutu, key community members, including leaders, participated in choosing the North Rupununi best practice, which guaranteed a very high impact in the process of implementation, despite all the other challenges met in this particular community. Leaders became aware of the main weakness of their community through the screening of the North Rupununi best practices, felt ashamed that they could not deal with community mobilization in the same way the North Rupununi communities did, became extremely motivated to implement this practice in their own community, and eventually made it happen. 
Table 5. Summary of best practice transfer impact perceived by COBRA participants.

\begin{tabular}{|c|c|c|c|c|}
\hline & $\begin{array}{l}\text { Level of best practice } \\
\text { implementation }\end{array}$ & $\begin{array}{l}\text { Main challenges in } \\
\text { implementation }\end{array}$ & $\begin{array}{l}\text { Main successes in } \\
\text { implementation }\end{array}$ & $\begin{array}{l}\text { Future best practice activities } \\
\text { envisaged }\end{array}$ \\
\hline Antecume Pata & $\begin{array}{l}\text { A local COBRA team } \\
\text { established and working in } \\
\text { community }\end{array}$ & $\begin{array}{l}\text { Poor organization of team, } \\
\text { support of leaders }\end{array}$ & $\begin{array}{l}\text { An organized team with } \\
\text { support from leaders }\end{array}$ & Unsure \\
\hline Katoonarib & $\begin{array}{l}\text { Culture group established } \\
\text { with various activities, } \\
\text { including campfire events, } \\
\text { dance, music, and costume- } \\
\text { making }\end{array}$ & Lack of resources & Community participation & $\begin{array}{l}\text { Developing more activities } \\
\text { linked to best practice }\end{array}$ \\
\hline Kavanayén & $\begin{array}{l}\text { Culture group established } \\
\text { with various activities, } \\
\text { including campfire events, } \\
\text { dance, music, and costume- } \\
\text { making }\end{array}$ & $\begin{array}{l}\text { Poor community } \\
\text { engagement }\end{array}$ & Community participation & $\begin{array}{l}\text { Developing more activities } \\
\text { linked to best practice }\end{array}$ \\
\hline Kwamalasamutu & $\begin{array}{l}\text { Village bridge rebuilt } \\
\text { through self-help }\end{array}$ & Does not say & Getting leaders support & $\begin{array}{l}\text { Apply principles to other } \\
\text { community issues }\end{array}$ \\
\hline Maturuca & $\begin{array}{l}\text { Establishment of community } \\
\text { radio agreed upon by } \\
\text { regional leaders; funding } \\
\text { request to local partners, } \\
\text { and research on licensing } \\
\text { and equipment carried out }\end{array}$ & Lack of resources & Community participation & $\begin{array}{l}\text { Developing more activities } \\
\text { linked to best practice }\end{array}$ \\
\hline
\end{tabular}

Another critical issue in engaging the wider community was team work and communication with the community. Local team members often did not believe enough in their ability to carry out the activities; they were shy, and afraid to fail, which made it much more difficult to engage the rest of the village. In Antecume Pata, where the local participants' team was young and inexperienced, many were frightened to talk with the leaders or take the initiative in organizing informative meetings with the wider community. As one Antecume Pata participant said, "For me it was difficult to present in front of people, it was the first time, I never did it before." As a consequence, there was significant reliance on the CSO support for taking on the community engagement process.

Group coordination was another relevant issue. As stated by a community facilitator in Katoonarib, "Group dynamics had been problematic in that the coordination of the activities was dependent on the specific persons assigned for the activity. Individuals felt that there was no proper coordination and group work and cooperation in general." In Kavanayén, participants formed a core group of highly motivated people who were already trying to implement some aspects of the best practice they chose before the arrival of the CP2PKE in the community. As a consequence, although people in the village were not always aware of the project context, the impact of all the activities developed to implement cultural transmission was very high.

\section{Transferability of best practices to the wider community}

The best practices presented from the North Rupununi were often found to be inspirational for the local participants as well as the community. Watching videos and photostories of how people in the North Rupununi managed to carry out successful practices enabled the communities to compare the North Rupununi situation with their own, be inspired, trigger some reflection, and be motivated to apply similar practices. It created a climate of solidarity as much as an atmosphere of "teaching," which supported the process in all contexts. The following quotes collected from people who attended community meetings illustrate this:

"I never had interest in culture, but when I saw the culture video [from North Rupununi] I became keen to do things I never had interest before, dances, language. It helped me become interested in my own culture. Before I wanted to learn Portuguese, but now I want to learn Wapishana-better to learn own language first before adapting to someone else's culture" (Katoonarib participant).

"Yes, it was interesting because they presented the posters they made, some stories about their village, I was happy to see these, it gives ideas to do some things" (participant, Antecume Pata).

"Liked looking at their [North Rupununi] videos/photos, got inspired by their culture video. Asked, why aren't we doing it?" (Katoonarib participant).

The CSO support observed the same phenomena, as they state in the following quotes:

"We consider that the training and exchange with the North Rupununi community was a catalyst and a stimulus to imitate the process undertaken by Project COBRA in other countries as Guyana and Suriname, in finding solutions and identifying challenges of the Kavanayén community" (CSO support, Kavanayén).

"The greatest impact was the realization that other indigenous peoples in similar geographical and cultural context, have advanced and reached significant levels of organization and leadership" (CSO support, Laguna Colorada).

Frequent screenings and communicating progress within the wider community helped build legitimacy within the communities and facilitated support of the whole process: villagers were less 
reluctant to be interviewed and were more motivated to participate. In Antecume Pata, for example, where the total engagement period was extremely short and community participation was challenging, the CP2PKE managed to attract some positive attention from villagers only at the end of the second visit: people became curious and came to observe progress, and the team finally began to see more participation at screenings.

\section{Peer-to-peer learning for making change}

In the contexts where greater team work and group interaction took place, our evaluation shows how participants and the wider community reached a new level of understanding of the challenges encountered in their communities and the potential solutions for addressing them. For example, in Antecume Pata and Kwamalasamutu, issues such as an unrepaired bridge or an unrepaired "tucuspan" (meeting house) were linked to issues of internal governance and community spirit rather than lack of funding from the government. The confidence to make a change was transmitted to communities, as solutions that were working in other (yet similar) contexts appealed to feelings of indigenous and community pride; communities observed that if other indigenous communities could do it, then surely they could do it as well. Furthermore, organizational skills were built, although they were not the explicit target of the CP2PKE. As a result of the confidence building, and the strengthening of knowledge and organizational capacity, the change linked to the implementation of the best practices was rapid. In all communities, within six months, a new practice was in place. For example, in Katoonarib and Kavanayén, a successful culture group was created, and in Kwamalasamutu, a bridge had been repaired within three months, thanks to the implementation of the "self-help" best practice.

In order to implement and document the best practices, participants and wider community members had to deal with issues related to community governance, management and planning, and communication. An important aspect of the best practice implementation was that the local participants and the wider community had to cope with these issues independently, with only limited support from the project staff members. This is maybe one of the most important outputs of this step of the CP2PKE, namely fostering enabling conditions for selfdetermination. Key soft skills, including strong leadership, good team management and planning, community togetherness, and communication, were identified by the local participants as key elements for implementing the best practices in their communities (Kaplan 2000, Black 2003, Mistry et al. 2009). Building key soft skills also contributed to building the confidence of many participants to take on new roles within their community. For example, young women in Kwamalasamutu were able to address male community leaders during public meetings, and express their concerns regarding their leadership capacity, in front of the North Rupununi indigenous facilitators. Without the confidence building during the community exchange, such encounters would not have happened.

Yet, we still felt that the timeframe for some of the interventions could have been longer. Although positive change occurred in all contexts, we found that six months was the bare minimum to ensure that the main outcomes of the initiative were reached, including the transferability of core concepts and techniques to participants and the wider community, and ensuring the successful implementation of a best practice to face up to a local challenge. For the practices that needed a significant initial input, such as implementing a community radio, six months was too short, and only the crucial initial guidelines could be transferred in order to motivate the community to get the task started. In addition, CP2PKE could have been reinforced through a two-way exchange where community members and participants visited the communities where the best practice was taking place (Patel and Mitlin 2002). In this case, the limitation was not only the timeframe but the resources available for this additional exchange. More broadly, the limited timeframe and resources available for the CP2PKE constrained the depth of the impact evaluation on the communities involved. We acknowledge that a more detailed process for social impact assessment for the community exchanges (Berardi 2013) that took into account factors such as deadweight, displacement, attribution, and drop-off, while locating the impact assessment within the interests and aims of the communities themselves rather than those of individual projects, could have been carried out. We hope to do this in future community interventions.

\section{DISCUSSION}

Our study, based on practical criteria for evaluating the impact of a CP2PKE process, provides important evidence for the range of enabling factors that not only ensure successful CP2PKE between communities but also contribute to meaningful impact of the exchange. This can help define optimal programs to further consolidate this innovative practice. This study therefore fills a crucial gap in research and provides a strong baseline for the development of similar initiatives, while acknowledging the limitations imposed by delimited project-based interventions.

Our impact assessment process paralleled recommendations for knowledge exchange evaluation made by Reed et al. (2014) and Fazey et al. (2014):

1. We focused on participants' priorities in terms of the challenges that the communities were facing and their own practices rather than our own predefinition of which challenges to address and which solutions to implement.

2. We built long-term, trusting relationships based on dialogue that went beyond "hit-and-run" interventions and instead focused on growing the relationship over an extended period of time, especially through working with established CSOs that had built these relationships before our CP2PKE process.

3. We delivered tangible results as soon as possible, with community participants being able to produce their own videos and photostories from the very first day of capacity building, and then on to the more important impact of implementing community owned solutions, which provided benefits to the wider community.

4. We applied an evaluation process that explored the impact on a variety of stakeholders, from participants involved in the capacity building (differentiated and analyzed in terms of, for example, age, gender, diverse capacity, and motivation) to the wider community, including the involvement of leaders.

5. We were explicit about how our CP2PKE was conceptualized and the assumptions we had in terms of expected outcomes. 
6. We evaluated a range of actual outcomes, some that were directly linked to the project objectives (e.g., implement a new practice in a community) and some that were not specifically outlined originally but clearly emerged during the process (e.g., the strengthening of self-confidence of young community members).

7. We used evaluations as part of the process of delivering the CP2PKE, which involved a wide variety of stakeholders in assessing the process and adapting it according to feedback.

8. We used mixed methods in the evaluation process, including one-to-one interviews, focus groups, observations, and peerto-peer interviews.

However, we also wanted to go beyond applying these generic "good practice" principles and identify more practical recommendations than those outlined by Reed et al. (2014) and Fazey et al (2014). In our approach, we were able to implement a relatively robust evaluation process for assessing the impact of our CP2PKE, and to therefore provide practical recommendations on how to increase the success of CP2PKE initiatives beyond generic principles of good practice.

Our results highlight a number of key criteria for maximizing the impact of a CP2PKE, such as the composition of the participants, the length of the exchange, and the role of collaborating CSOs. However, critical to the success of the exchange was the role of community facilitators. Research shows that individuals may be more likely to view information produced by those with similar interests as more credible and legitimate (e.g., Henry and Dietz 2011, Moeliono et al. 2014), and may also exhibit homophily, namely the tendency for people to interact with people similar to themselves (McPherson et al. 2001). Establishing a common understanding of concepts and tools through the community facilitators was also crucial. Our use of "foreign" concepts such as system viability became locally owned through sharing concepts and tools, and readapting them to local necessities and views. However, there are major dangers with this approach too. We faced the potential risks of "facipulation" when promoting concepts and techniques developed within the globalizing modern cultural context; i.e., giving a participatory and grassroots guise to a process with the subtle aim of transferring non-indigenous concepts, such as system viability, and ICT tools, such as videos and laptops, which may not, in fact, be compatible with the local cultural context (White and Tiongco 1997). We have debated this issue elsewhere (Berardi et al. 2014b), but suffice to say that the process we adopted prioritized freedom for the communities themselves to choose how the concepts and techniques were adapted and implemented on their own terms.

Participants' capacity in ICT and community infrastructure, such as access to the Internet, in many cases was limited, which made the use of participatory visual techniques and methods challenging. Nevertheless, starting from the initial capacity building training, participatory films and photostories played a fundamental role in producing tangible outputs, which helped focus and motivate participants to undertake activities, while at the same time enabling sharing of progress with the wider community. We found that the use of PV and PP enabled participants to gain new technical capacity but also to analyze their local practices with a new angle and gain ownership of the core concepts and techniques of the project. It is clear that as ICT communication networks and technologies become more accessible and participants become more skilled in their use, the drawbacks of using techniques such as PV and PP will diminish, with the real prospects of these techniques becoming a core part of communities' day-to-day lives and any eventual CP2PKE process. However, in our practitioner manual that underpins the process, we also suggest that advanced ICT technologies may not always be appropriate in the CP2PKE process, and that more accessible communication tools, such as hand drawings, could be used (Berardi et al. 2014a).

The focus on self-determined challenges proved to be a key step of the process. Only once the community challenges were identified could the North Rupununi best practice be chosen and implemented by the local communities. The community owned approach, especially when involving the wider community, was critical for community motivation and ownership of the process. We have started a chain of action that we hope will open opportunities for communities of the Guiana Shield to be the instigators of exchange processes. We have already seen some signs of this: the community of Maturuca is pursuing exchanges with the North Rupununi and has independently organized internships to the North Rupununi to explore ecotourism and learning languages, and at the same time has invited North Rupununi students to study vegetable growing in their agricultural school. Community-to-community knowledge exchange constitutes a unique opportunity to find alternative ways of dealing with climate change and complex social-ecological challenges. It also provides one of the most ethically appropriate frameworks to engage research and carry out projects with indigenous communities, and deconstruct conventional Western knowledge (Smith 2012).

\section{CONCLUSION}

Many environmental management and governance policies are unclear with regard to how the expenditure of funds for the protection and enhancement of the environment is going to be spent within the receiving institutions and communities. Our analyses show that peer-to-peer knowledge exchange for supporting and sharing community owned solutions holds great promise for successful and sustainable environmental management in the Guiana Shield. Within a context characterized by indigenous communities as the key mediators, providing funding to first identify and then help strengthen community owned solutions through peer-to-peer knowledge exchange would be an effective mechanism for addressing the needs of protecting the environment while empowering indigenous communities and integrating traditional sustainable livelihoods with innovations that would actually promote, rather than undermine, community cohesion and indigenous culture.

Responses to this article can be read online at: http://www.ecologyandsociety.org/issues/responses. $\mathrm{php} / 8495$ 


\section{Acknowledgments:}

We would like to especially thank the COBRA participants and the communities of the North Rupununi (Guyana), Kwamalasamutu (Suriname), Kavanayén (Venezuela), Katoonarib (Guyana), Laguna Colorada (Colombia), Maturuca (Brazil), and Antecuma Pata (French Guiana) for their enthusiastic participation in this research. We would also like to thank the following practitioners and academics for helping facilitate the exchanges and for their insightful inputs into the process: Rachelle Bong A Jan and Gwendolyn Smith of Attune Development, Suriname; Bibiana Bilbao and Adriana Millan of the Universidad Simón Bolivar, Venezuela; Vincenzo Lauriola of the Instituto Nacional de Pesquisas da Amazonia, Brazil; Jorge Restrepo and Sandra Aristizabal of the United Nations Development Programme, Colombia; Aurélia Stefani of the Université des Antilles et de la Guyane, Institut Pasteur, French Guiana; Claire Couly of the Parc Amazonien de Guyane, French Guiana; and Nicholas Fredericks and Faye Fredericks of the South Central People's Development Association, Guyana. We thank the reviewers for their pertinent comments, which greatly helped improve the paper. This research was funded by the Environment Programme, Management of Natural Resources, DG Research and Innovation, European Commission 7th Framework.

\section{LITERATURE CITED}

Armitage, D., F. Berkes, and N. Doubleday, editors. 2007. Adaptive co-management: collaboration, learning, and multi-level governance. University of British Columbia Press, Vancouver, British Columbia, Canada.

Armitage, D., M. Marschke, and R. Plummer. 2008. Adaptive comanagement and the paradox of learning. Global Environmental Change 18(1):86-98. http://dx.doi.org/10.1016/j.gloenvcha.2007.07.002

Berardi, A. 2013. Social impact assessment and the COBRA project. Working paper, May 2013. [online] URL: https://www. academia.edu/3999151/Social_Impact_Assessment_and the COBRA project

Berardi, A., E. Bignante, J. Mistry, M. Simpson, C. Tschirhart, C. Verwer, and G. de Ville. 2014a. How to find \& share community owned solutions. A handbook. [online] URL: http://projectcobra. org/how-to-find-and-share-community-owned-solutions

Berardi, A., J. Mistry, C. Tschirhart, J. Abraham, and E. Bignante. 2012. Report on the cross-scalar interactions and compatibilities governing sustainable development and ecosystem service management of the Guiana Shield. The Open University. [online] URL: http://projectcobra.org/wp-content/uploads/D2.1Reportoncrossscalarinteractionsandcompatibilities3.pdf

Berardi, A., J. Mistry, C. Tschirhart, E. Bignante, O. Davis, L. Haynes, R. Benjamin, G. Albert, R. Xavier, D. Jafferally, and G. De Ville. 2015. Applying the system viability framework for crossscalar governance of nested social-ecological systems in the Guiana Shield, South America. Ecology and Society 20(3):42. http://dx.doi.org/10.5751/ES-07865-200342

Berardi, A., J. Mistry, C. Tschirhart, E. Bignante, L. Haynes, and D. Jafferally. 2014b. The COBRA Project: a community-based approach to public engagement in science. Proceedings of the $13 \mathrm{th}$
International Public Communication of Science and Technology Conference. 5-8 May 2014, Salvador, Brazil.

Berardi, A., J. Mistry, C. Tschirhart, C. Verwer, R. Glastra, G. de Ville, O. Davis, C. de Souza, L. Haynes, R. Benjamin, R. Xavier, G. Albert, D. Jafferally, E. Bignante, and J. Abraham. $2013 a$. Second report on the cross-scalar interactions and compatibilities governing sustainable development and ecosystem service management of the Guiana Shield: drivers of social and environmental degradation, and policy responses. The Open University. [online] URL: http://projectcobra.org/second-reporton-cross-scalar-actions-and-compatibilities/

Berardi, A., C. Tschirhart, J. Mistry, E. Bignante, L. Haynes, G. Albert, R. Benjamin, R. Xavier, and D. Jafferally. 2013b. From resilience to viability: a case study of indigenous communities of the North Rupununi, Guyana. EchoGéo 24. [online] URL: http:// echogeo.revues.org/13411

Berkes, F. 2007. Community-based conservation in a globalized world. Proceedings of the National Academy of Sciences of the United States of America 104:15188-15193. http://dx.doi. org/10.1073/pnas.0702098104

Bignante, E. 2010. The use of photo elicitation in field research: exploring Maasai representation and use of natural resources. EchoGéo 11. [online] URL: https://echogeo.revues.org/11622? lang=en http://dx.doi.org/10.4000/echogeo.11622

Black, L. 2003. Critical review of the capacity-building literature and discourse. Development in Practice 13(1):116-120. http://dx. doi.org/10.1080/0961452022000038017

Eade, D. 2007. Capacity building: who builds whose capacity? Development in Practice 17(4-5):630-639. http://dx.doi. org/10.1080/09614520701469807

Fazey, I., L. Bunse, J. Msika, M. Pinke, K. Preedy, A. C. Evely, E. Lambert, E. Hastings, S. Morris, and M. S. Reed. 2014. Evaluating knowledge exchange in interdisciplinary and multistakeholder research. Global Environmental Change 25:204-220. http://dx.doi.org/10.1016/j.gloenvcha.2013.12.012

Fu, Y., R. E. Grumbine, A. Wilkes, Y. Wang, J. Xu, and Y. Yang. 2012. Climate change adaptation among Tibetan pastoralists: challenges in enhancing local adaptation through policy support. Environmental Management 50(4):607-621. http://dx.doi.org/10.1007/ s00267-012-9918-2

Henry, A. D., and T. Dietz. 2011. Information, networks, and the complexity of trust in common governance. International Journal of the Commons 5(2):188-212. http://dx.doi.org/10.18352/ijc.312

Kaplan, A. 2000. Capacity building: shifting the paradigms of practice. Development in Practice 10(3-4):517-526. http://dx.doi. org/10.1080/09614520050116677

Kapoor, I. 2001. Towards participatory environmental management? Journal of Environmental Management 63(3):269279. http://dx.doi.org/10.1006/jema.2001.0478

Kindon, S. L., R. Pain, and M. Kesby, editors. 2007. Participatory action research approaches and methods: connecting people, participation and place. Routledge, Abingdon, UK.

Lunch, N., and C. Lunch. 2006. Insights into participatory video. InsightShare, Oxford, UK. 
Mauser, W., G. Klepper, M. Rice, B. S. Schmalzbauer, H. Hackmann, R. Leemans, and H. Moore. 2013. Transdisciplinary global change research: the co-creation of knowledge for sustainability. Current Opinion in Environmental Sustainability 5:420-431. http://dx.doi.org/10.1016/j.cosust.2013.07.001

McPherson, M., L. Smith-Lovin, and J. M. Cook. 2001. Birds of a feather: homophily in social networks. Annual Review of Sociology 27:415-444. http://dx.doi.org/10.1146/annurev.soc.27.1.415

Measham, T. G., and J. A. Lumbasi. 2013. Success factors for community-based natural resource management (CBNRM): lessons from Kenya and Australia. Environmental Management 52(3):649-659. http://dx.doi.org/10.1007/s00267-013-0114-9

Mistry, J., and A. Berardi. 2012. The challenges and opportunities of participatory video in geographical research: a case study exploring collaboration with indigenous communities of the North Rupununi, Guyana. Area 44:110-116. http://dx.doi. org/10.1111/j.1475-4762.2011.01064.X

Mistry, J., A. Berardi, E. Bignante, and C. Tschirhart. $2015 b$. Between a rock and a hard place: ethical dilemmas of local community facilitators doing participatory research projects. Geoforum 61:27-35. http://dx.doi.org/10.1016/j.geoforum.2015.02.010

Mistry, J., A. Berardi, I. Roopsind, O. Davis, L. Haynes, O. Davis, and M. Simpson. 2011. Capacity building for adaptive management: a problem-based learning approach. Development in Practice 21(2):190-204. http://dx.doi.org/10.1080/09614524.2$\underline{011.543272}$

Mistry, J., A. Berardi, and M. Simpson. 2009. Critical reflections on practice: the changing roles of three physical geographers carrying out research in a developing country. Area 41(1):82-93. http://dx.doi.org/10.1111/j.1475-4762.2008.00841.x

Mistry, J., A. Berardi, C. Tschirhart, E. Bignante, L. Haynes, R. Benjamin, G. Albert, R. Xavier, D. Jafferally, and G. de Ville. $2015 a$. Indigenous identity and environmental governance in Guyana, South America. Cultural Geographies 22(4):689-712. http://dx.doi.org/10.1177/1474474014560998

Mistry, J., A. Berardi, C. Tschirhart, E. Bignante, L. Haynes, R. Benjamin, G. Albert, R. Xavier, B. Robertson, O. Davis, D. Jafferally, and G. De Ville. 2016. Community owned solutions: identifying local best practices for social-ecological sustainability. Ecology and Society 21(2):42. http://dx.doi.org/10.5751/ ES-08496-210242

Mistry J., E. Bignante, and A. Berardi. 2014b. Why are we doing it? Negotiating expectations in the participatory video process. Area http://dx.doi.org/10.1111/area.12105

Mistry, J., C. Tschirhart, and A. Berardi. 2013b. Report on best practice case studies. Royal Holloway and Bedford New College, University of London, UK. [online] URL: http://projectcobra. org/wp-content/uploads/WP4-BestPracticesReport.pdf

Mistry, J., C. Tschirhart, C. Verwer, R. Glastra, O. Davis, D. Jafferally, L. Haynes, R. Benjamin, G. Albert, R. Xavier, I. Bovolo, I., and A. Berardi. 2014a. Our common future? Cross-scalar scenario analysis for social-ecological sustainability of the Guiana Shield, South America. Environmental Science \& Policy 44:126-148.
Mistry, J., C. Verwer, C. Tschirhart, R. Glastra, O. Davis, D. Jafferally, and I. Bovolo. 2013a. Report on the cross-scalar socialecological scenarios of the Guiana Shield. Royal Holloway and Bedford New College, University of London, UK. [online] URL: http://projectcobra.org/wp-content/uploads/WP3Report.pdf

Moeliono, M., C. Gallemore, L. Santoso, M. Brockhaus, and M. Di Gregorio. 2014. Information networks and power: confronting the "wicked problem" of REDD+ in Indonesia. Ecology and Society 19(2):9. http://dx.doi.org/10.5751/ES-06300-190209

Newsham, A. J., and D. S. G. Thomas. 2011. Knowing, farming and climate change adaptation in north-central Namibia. Global Environmental Change 21(2):761-770. http://dx.doi.org/10.1016/ j.gloenvcha.2010.12.003

Olsson, P., and C. Folke. 2001. Local ecological knowledge and institutional dynamics for ecosystem management: a study of Lake Racken Watershed, Sweden. Ecosystems 4(2):85-104. http:// dx.doi.org/10.1007/s100210000061

Olsson, P., C. Folke, and F. Berkes. 2004. Adaptive comanagement for building resilience in social-ecological systems. Environmental Management 34(1):75-90. http://dx.doi.org/10.1007/s00267-003-0101-7

Palmer Fry, B., M. Agarwala, G. Atkinson, T. Clements, K. Homewood, S. Mourato, J. M. Rowcliffe, G. Wallace, and E. J. Milner-Gulland. 2015. Monitoring local well-being in environmental interventions: a consideration of practical tradeoffs. Oryx http://dx.doi.org/10.1017/S003060531500112X.

Patel, S., and D. Mitlin. 2002. Sharing experiences and changing lives. Community Development Journal 37(2):125-136. http://dx. doi.org/10.1093/cdj/37.2.125

Reed, M. S., L. C. Stringer, I. Fazey, A. C. Evely, and J. H. J. Kruijsen. 2014. Five principles for the practice of knowledge exchange in environmental management. Journal of Environmental Management 146:337-345. http://dx.doi.org/10.1016/j. jenvman.2014.07.021

Rodríguez, J. P., K. M. Rodríguez-Clark, M. A. OliveiraMiranda, T. Good, and A. Grajal. 2006. Professional capacity building: the missing agenda in conservation priority setting. Conservation Biology 20(5):1340. http://dx.doi.org/10.1111/ j.1523-1739.2006.00535_1.x

Smith, L. T. 2012. Decolonizing methodologies: research and indigenous peoples. Zed Books, London, UK.

Tschirhart, C., J. Mistry, M. Simpson, A. Berardi, C. Verwer, G. de Ville, and E. Bignante. 2014. Report on best practice sharing, implementation and evaluation. Royal Holloway and Bedford New College, University of London, UK. [online] URL: http:// projectcobra.org/work-package-5-report

United Nations Development Programme (UNDP). 2014. Facilitating local learning and knowledge exchange. [online] URL: http://www.undp.org/content/undp/en/home/ourwork/ environmentandenergy/strategic themes/local development/ facilitating locallearningandknowledgeexchange/

Wahbe, T. R., E. M. Jovel, D. R. Silva Garcia, V. E. Pilco Llagcha, and N. R. Point. 2007. Building international indigenous people's partnerships for community-driven health initiatives. EcoHealth 4(4):472-488. http://dx.doi.org/10.1007/s10393-007-0137-x 
Ecology and Society 21(2): 41

White, S. C., and R. Tiongco. 1997. Doing theology and development: meeting the challenge of poverty. Saint Andrew Press, Edinburgh, Scotland.

World Bank. 2015. Africa region indigenous knowledge for development program, community knowledge exchange toolkit. [online] URL: http://www.worldbank.org/afr/ik/commun toolkit/ Toolkit1/introductionI.htm 